\title{
Overgewicht, obesitas en verzuim in de Nederlandse werkende bevolking
}

\author{
MP Jans ${ }^{1}$, SG van den Heuvel ${ }^{2}$, VH Hildebrandt ${ }^{1,3}$, PM Bongers ${ }^{2,3}$
}

\begin{abstract}
Doel: Nagaan of Nederlandse werknemers met overgewicht of obesitas een hogere verzuimfrequentie en langere verzuimduur hebben dan werknemers met een normaal gewicht, en de invloed van sportdeelname hierop. Methode: De gegevens zijn afkomstig van een longitudinaal cohort onderzoek in een werkende populatie $(n=1284)$. De verzuimdata zijn door het bedrijf geregistreerd. Multilevelanalyses zijn toegepast om te testen of de verzuimduur en verzuimfrequentie samenhingen met de Body Mass Index (BMI) en of de interactie van BMI en regelmatige sportdeelname een significante relatie had met verzuim. Resultaten: Werknemers met overgewicht (BMI 25-30) hadden alleen een significant hogere middellange verzuimfrequentie dan werknemers met een normaal gewicht $(\mathrm{p}<0,005)$. Obese werknemers $(\mathrm{BMI} \geq 30)$ verzuimden 14 dagen per jaar meer dan werknemers met een normaal gewicht $(\mathrm{p}<0,005)$. Ook de middellange en lange verzuimfrequentie lagen significant hoger $(\mathrm{p}<0,005)$. De verschillen tussen werknemers met obesitas en een normaal gewicht waren groter bij hen die niet regelmatig sportten. Deze interactie tussen BMI en regelmatige sportdeelname was alleen significant voor het lange verzuim. Conclusies: Obese werknemers verzuimen vaker en langer, vooral wanneer zij niet regelmatig sporten. Een actief bedrijfsbeleid gericht op de preventie van overgewicht en obesitas is gewenst, zowel vanuit gezondheidskundig oogpunt als vanuit het oogpunt van het bedrijfsrendement.
\end{abstract}

Trefwoorden: obesitas, overgewicht, verzuim, sport, longitudinaal onderzoek

\section{INLEIDING}

Momenteel heeft bijna de helft van de volwassen Nederlandse populatie overgewicht en is ruim $10 \%$ obees. ${ }^{1}$ Mensen met overgewicht en obesitas sterven eerder en hebben een groter risico op het krijgen van chronische ziekten, zoals diabetes type 2 , kanker en aandoeningen aan het bewegingsapparaat. ${ }^{2,3}$ De jaarlijkse directe kosten voor de gezondheidszorg als gevolg van overgewicht en obesitas werden in 1999 in Nederland al geschat op een half miljard euro. ${ }^{4}$ Deze kosten zullen nu hoger liggen, aangezien de prevalentie van overgewicht en obesitas in de afgelopen jaren verder is toegenomen. ${ }^{5}$ Overgewicht en obesitas kunnen ook allerlei negatieve arbeidsgebonden effecten hebben, zoals verminderde productiviteit, hoger ziekteverzuim en toename van arbeidsongeschiktheidsuitkeringen. In 2002 schatte de Raad voor de Volksgezondheid en Zorg deze indirecte kosten in Nederland op twee miljard euro per jaar. ${ }^{6}$

Preventie van overgewicht krijgt de laatste jaren steeds meer aandacht. Tot nu toe is het vooral de overheid die

\footnotetext{
TNO Kwaliteit van Leven, Leiden

2 TNO Kwaliteit van Leven, Hoofddorp

3 Body@Work Onderzoekscentrum Bewegen, Arbeid en Gezondheid, TNO-VUmc
}

hier aandacht voor heeft, waarbij de gezondheidskundige invalshoek prevaleert. Toch is het de vraag of het bedrijfsleven zich dit probleem niet ook moet aantrekken. Als de prognoses uitkomen dat overgewicht en obesitas de komende jaren in omvang sterk zullen toenemen, dan heeft het bedrijfsleven er de komende jaren een zorg bij, aangezien verwacht mag worden dat de indirecte kosten als gevolg hiervan ook gaan toenemen. Lange tijd vonden werkgevers dat zij hun werknemers niet konden aanspreken op hun ongezonde leefstijl. Dat werd als een privé-zaak gezien. Maar er is een kentering gaande: recentelijk hebben VNO-NCW en MKB-Nederland het Convenant Overgewicht mede ondertekend en daarmee de intentie uitgesproken bij te dragen aan de preventie van overgewicht.

Werkgevers hebben mogelijk een direct belang om bij te dragen aan de preventie van overgewicht als duidelijk is aangetoond dat dit leidt tot minder verzuim. Twee Amerikaanse reviews van buitenlandse onderzoeken concluderen dat overgewicht en obesitas een significante relatie hebben met ziekteverzuim. ${ }^{7,8}$ Deze relatie is echter vooral gebaseerd op cross-sectionele onderzoeken. ${ }^{9-15}$ Een nadeel van cross-sectioneel onderzoek is dat niet duidelijk is wat oorzaak en gevolg is: verzuim kan veroorzaakt worden door obesitas, maar andersom kan ook het geval zijn. 
Dit nadeel is minder aanwezig in longitudinale onderzoeken en die studies zijn schaars.

In Nederland is nog geen onderzoek gedaan naar de relatie tussen Body Mass Index (BMI) en verzuim. Om deze relatie te onderzoeken is in het onderhavige onderzoek gebruik gemaakt van een Nederlands longitudinaal onderzoek, waarin de verzuimdata afkomstig zijn uit verzuimregistraties van de deelnemende bedrijven. Bovendien wordt onderscheid gemaakt in kort en lang verzuim, zodat duidelijk wordt welke vorm van verzuim vooral samenhangt met overgewicht en obesitas.

Volgens internationale richtlijnen moet de behandeling van obesitas in eerste instantie gericht zijn op een blijvend gewichtsverlies van ongeveer $10 \%$. Met dit relatief geringe gewichtsverlies kan al een belangrijke gezondheidswinst worden behaald. ${ }^{3}$ Gezonde voeding en meer bewegen spelen hierbij een belangrijke rol. Bij obesitas is er immers sprake van een langdurig positieve energiebalans, samenhangend met te weinig lichamelijke activiteit en/of een te hoge energie-inname. In eerder onderzoek is reeds aangetoond dat lichamelijke activiteit de negatieve gezondheidseffecten van obesitas kan reduceren. ${ }^{16}$ Ook is aangetoond dat de mate van lichamelijke activiteit samenhangt met verzuim. ${ }^{17}$ Daarom is in het onderhavige onderzoek - naast de relatie tussen BMI en verzuim - ook gekeken of deze relatie minder sterk is bij werknemers die regelmatig sporten. Door het ontbreken van gegevens over energie-inname in het databestand kon de mogelijke invloed daarvan niet in deze analyse betrokken worden.

De volgende vraagstellingen worden beantwoord:

1 Hebben werknemers met overgewicht of obesitas een hogere verzuimfrequentie en langere verzuimduur dan werknemers met een normaal gewicht?

2 Is de relatie tussen overgewicht/obesitas en verzuim minder sterk bij werknemers die regelmatig sporten dan bij hen die niet regelmatig sporten?

\section{METHODE}

\section{Onderzoekspopulatie}

Voor dit onderzoek zijn gegevens gebruikt van een longitudinaal cohort onderzoek naar werkgebonden risicofactoren voor klachten aan het bewegingsapparaat. ${ }^{18}$ De onderzoekspopulatie bestond uit 1742 werknemers, in de leeftijd van 18 tot 59 jaar, die minimaal 24 uur per week werkten. Zij waren afkomstig uit 34 verschillende bedrijven uit de industriële, administratieve en dienstverlenende sector. ${ }^{18}$ Voor dit onderzoek zijn de gegevens van 1284 werknemers gebruikt met complete gegevens over geslacht, BMI en verzuim. De grote uitval is vooral ver- oorzaakt doordat 13 van de 34 deelnemende bedrijven geen adequate gegevens over verzuim (geen of onvolledige gegevens) konden aanleveren. De Medisch Ethische Commissie van TNO heeft het onderzoek goedgekeurd.

\section{Dataverzameling}

De basismeting vond in 1994 plaats, gevolgd door drie follow-up metingen in 1995, 1996 en 1997. De gegevens zijn verzameld met behulp van vragenlijsten, fysieke metingen en verzuimregistraties door het bedrijf. Gegevens over leeftijd, geslacht, opleidingsniveau, roken, alcoholconsumptie, type werk en sportdeelname zijn verzameld tijdens de basismeting met behulp van een vragenlijst. Met de variabele 'type werk' is onderscheid gemaakt tussen werknemers die veel zittend werk deden en werknemers die slechts 'zelden' of 'af en toe' zittend werk deden ten tijde van de basismeting. Om sportdeelname te bepalen, is gevraagd of de werknemers in het jaar voorafgaande aan de basismeting fysiek inspannende sporten hadden gedaan en zo ja, wat de frequentie van deelname was. Er is onderscheid gemaakt tussen werknemers die wel en niet regelmatig sporten. Regelmatige sportdeelname is gedefinieerd als tenminste één keer per week gedurende tenminste tien maanden fysiek inspannend sporten in het jaar voorafgaande aan de basismeting.

Om overgewicht en obesitas te bepalen is de BMI berekend als het gewicht (in kg) gedeeld door de lengte (in $\mathrm{m}$ ) in het kwadraat. Tijdens de basismeting zijn lichaamslengte en lichaamsgewicht gemeten. De werknemers hadden tijdens de metingen geen zware kleding of schoenen aan. De WHO criteria ${ }^{2}$ zijn gebruikt voor de classificatie in 'ondergewicht' (BMI $<18,5 \mathrm{~kg} / \mathrm{m}^{2}$ ), 'normaal gewicht' (BMI 18,5-24,9 kg/m²), 'overgewicht' $\left(\right.$ BMI $\left.25,0-29,9 \mathrm{~kg} / \mathrm{m}^{2}\right)$ en 'obesitas' $\left(\mathrm{BMI} \geq 30,0 \mathrm{~kg} / \mathrm{m}^{2}\right)$.

Voor de effectmaat verzuim zijn de geregistreerde verzuimgegevens van het jaar voorafgaande aan de basismeting en de drie follow-up jaren gebruikt. Deze gegevens zijn jaarlijks verzameld en aangeleverd door 21 van de 34 deelnemende bedrijven. Werknemers hebben toestemming gegeven voor het gebruik van hun verzuimgegevens voor het onderzoek. Uit deze gegevens zijn duur en frequentie van het verzuim berekend over de vier jaar van het onderzoek. Voor de frequentie is onderscheid gemaakt in de frequentie van zeer kort verzuim ( 1 tot 2 dagen), kort verzuim (3 tot 7 dagen), middellang verzuim ( 8 tot 21 dagen) en lang verzuim (meer dan 21 dagen).

\section{Statistische analyses}

Aangezien ondergewicht weinig voorkwam in deze populatie (19 werknemers) en niet het onderwerp van dit onderzoek was, zijn de werknemers met ondergewicht niet meegenomen in de analyses. Descriptieve analyses 
zijn gebruikt om de achtergrondkenmerken van werknemers met normaal gewicht, overgewicht en obesitas te beschrijven. Daarna zijn per BMI-categorie gemiddelden berekend van verzuimduur, verzuimfrequentie over de totale meetperiode van vier jaar. Met behulp van multilevelanalyses is getest of de BMI-categorieën significant samenhingen met één van de verzuimmaten, waarbij gecorrigeerd is voor leeftijd, geslacht, opleidingsniveau, type werk, roken en alcoholconsumptie. In de multilevelanalyse is rekening gehouden met de clustering op bedrijfsniveau. Aangezien de verzuimmaten zeer scheef verdeeld waren, zijn de uitkomstmaten getransformeerd naar een bij benadering normale verdeling. Om na te gaan of regelmatige sportdeelname invloed heeft op de relatie tussen BMI en verzuim, zijn vervolgens gestratificeerde multilevelanalyses uitgevoerd voor werknemers die regelmatig en niet regelmatig sportten en is getoetst of de interactie van BMI en sporten een significante relatie heeft met verzuim.

\section{RESULTATEN}

\section{Achtergrondkenmerken}

Van de 1284 werknemers had 32\% overgewicht en 7\% obesitas. In tabel 1 zijn per BMI-categorie de achtergrondkenmerken tijdens de basismeting beschreven. Hieruit blijkt dat werknemers met overgewicht of obesitas minder vaak zittend werk hadden dan werknemers met een normaal gewicht. Daarnaast waren ze ouder en minder vaak 'huidige rokers', hoewel ze wel vaker in het verleden gerookt hadden. Overgewicht kwam bij mannen vaker voor dan bij vrouwen. De werknemers met obesitas waren lager opgeleid dan werknemers met een normaal gewicht of overgewicht.

\section{BMI en verzuim}

Tabel 2 laat de gemiddelde verzuimfrequentie en verzuimduur zien van werknemers met een normaal gewicht, overgewicht en obesitas. Voor werknemers met overgewicht was alleen de verzuimfrequentie van het middellange verzuim significant hoger dan bij werknemers met een normaal gewicht. Obese werknemers verzuimden significant vaker èn meer dagen dan werknemers met een normaal gewicht. Gemiddeld verzuimden obese werknemers 14 dagen per jaar (55 dagen per 4 jaar) meer dan werknemers met een normaal gewicht. De frequentie van het zeer korte en korte verzuim was niet gerelateerd aan obesitas.

\section{Invloed van sportdeelname}

De stratificatie voor sportdeelname laat zien dat in de groep werknemers zonder regelmatige sportdeelname, obesitas samenhing met een langere verzuimduur en een hogere verzuimfrequentie van verzuim langer dan acht dagen (tabel 3). In deze groep verzuimden obese werknemers gemiddeld 15,5 dag per jaar meer dan werknemers met een normaal gewicht. In de groep werknemers met regelmatige sportdeelname zijn geen significante relaties gevonden tussen de BMI en verzuim. De interactie van BMI en sportdeelname was alleen significant voor het lange verzuim $(\mathrm{p}=0,05)$.

\section{Discussie}

Uit de resultaten blijkt dat obese werknemers vaker en langer verzuimen dan werknemers met een normaal gewicht. De verschillen betreffen alleen het middellange en lange verzuim (acht dagen of langer). Werknemers met overgewicht hebben alleen een hogere frequentie van het middellange verzuim dan werknemers met een normaal gewicht. De gevonden relatie tussen BMI en verzuim bevestigen de bevindingen uit buitenlandse cross-sectionele onderzoeken ${ }^{7,8}$ en één negenjarig longitudinaal onderzoek in één bedrijf in de VS. In die studie hadden obese werknemers $\left(\right.$ BMI $\left.>27 \mathrm{~kg} / \mathrm{m}^{2}\right)$ een hogere verzuimfrequentie en verzuimduur in vergelijking met nietobese werknemers. ${ }^{19}$ In het enige andere beschikbare longitudinale onderzoek, een éénjarig onderzoek binnen 25 bedrijven in België, werd echter geen relatie gevonden tussen BMI en verzuim. Wel bleek de buikomvang een onafhankelijke voorspeller te zijn van verzuimduur en van langdurig verzuim. ${ }^{20}$

Deze twee longitudinale onderzoeken hebben door het bedrijf geregistreerde verzuimdata gebruikt, maar in de meeste cross-sectionele onderzoeken zijn zelfgerapporteerde verzuimdata gebruikt. ${ }^{9,13,14,15}$ De nauwkeurigheid van zelfgerapporteerde verzuimdata neemt af naarmate de periode waarover wordt teruggevraagd langer wordt. Daarom hebben door het bedrijf geregistreerde verzuimdata de voorkeur. ${ }^{21-23}$ Een andere tekortkoming in veel cross-sectionele onderzoeken is dat het gewicht en de

Tabel 1 Type werk, leefstijl en andere achtergrondkenmerken, opgedeeld naar drie categorieën van de Body Mass Index.

\begin{tabular}{|c|c|c|c|c|}
\hline & $\begin{array}{l}\text { Totale groep } \\
\quad(n=1191)\end{array}$ & $\begin{array}{c}\text { Normaal ge- } \\
\text { wicht }^{1}(n=722)\end{array}$ & $\begin{array}{c}\text { Overgewicht }^{2} \\
(n=382)\end{array}$ & $\begin{array}{c}\text { Obesitas }^{3} \\
(\mathrm{n}=87)\end{array}$ \\
\hline Type werk (\% zittend werk) & 40 & 42 & 37 & 33 \\
\hline Alcoholconsumptie (\% meer dan 20 glazen/week) & 7 & 8 & 7 & 5 \\
\hline \multicolumn{5}{|l|}{ Roken } \\
\hline - Vroeger gerookt (\%) & 26 & 21 & 33 & 33 \\
\hline - Rookt nu (\%) & 43 & 45 & 39 & 37 \\
\hline Regelmatige sportdeelname (\%) & 29 & 30 & 28 & 25 \\
\hline Geslacht (\% vrouwen) & 29 & 34 & 19 & 33 \\
\hline Leeftijd (gemiddelde (SD)) & $36(9)$ & $34(8)$ & $38(9)$ & $39(8)$ \\
\hline \multicolumn{5}{|l|}{ Opleidingsniveau } \\
\hline$-\operatorname{Laag}(\%)$ & 53 & 49 & 55 & 72 \\
\hline - Gemiddeld (\%) & 27 & 29 & 27 & 21 \\
\hline$-\operatorname{Hoog}(\%)$ & 20 & 22 & 18 & 7 \\
\hline
\end{tabular}

${ }^{1} \mathrm{BMI} 18,5-24,9 \mathrm{~kg} / \mathrm{m}^{2} ;{ }^{2} \mathrm{BMI} 25,0-29,9 \mathrm{~kg} / \mathrm{m}^{2} ;{ }^{3} \mathrm{BMI} \geq 30,0 \mathrm{~kg} / \mathrm{m}^{2}$ 
Tabel 2 Gemiddelde verzuimcijfers over de vierjarige onderzoeksperiode voor werknemers met een normaal gewicht, overgewicht of obesitas.

\begin{tabular}{|c|c|c|c|c|}
\hline Ziekteverzuim \# & $\begin{array}{l}\text { Totale groep } \\
\quad(n=1191)\end{array}$ & $\begin{array}{l}\text { Normaal gewicht }^{1} \\
\quad(n=722)\end{array}$ & $\begin{array}{l}\text { Overgewicht }{ }^{2} \\
\quad(n=382)\end{array}$ & $\begin{array}{c}\text { Obesitas }^{3} \\
(n=87)\end{array}$ \\
\hline Frequentie zeer kort verzuim (1-2 dagen) & 1,6 & 1,8 & 1,3 & 1,3 \\
\hline Frequentie kort verzuim (3-7 dagen) & 3,2 & 3,2 & 3,0 & 3,6 \\
\hline Frequentie middellang verzuim (8-21 dagen) & 1,4 & 1,3 & $1,6^{\star \star}$ & $2,1^{\star \star}$ \\
\hline Frequentie lang verzuim ( $\geq 22$ dagen) & 0,7 & 0,7 & 0,7 & $1,2^{\star \star}$ \\
\hline Frequentie totale verzuim & 6,9 & 6,9 & 6,6 & $8,2^{\star}$ \\
\hline Totale verzuimduur (in dagen) & 84,6 & 78,3 & 85,6 & $133,1^{\star \star}$ \\
\hline
\end{tabular}

${ }^{1} \mathrm{BMI} 18,5-24,9 \mathrm{~kg} / \mathrm{m}^{2} ;{ }^{2} \mathrm{BMI} 25,0-29,9 \mathrm{~kg} / \mathrm{m}^{2} ;{ }^{3} \mathrm{BMI} \geq 30,0 \mathrm{~kg} / \mathrm{m}^{2}$

${ }^{\star} \mathrm{p}<0,05 ;{ }^{\star \star} \mathrm{p}<0,005$ obesitas/overgewicht versus normaal gewicht (multilevel analyse met bedrijf als cluster, en gecorrigeerd voor leeftijd, geslacht, opleidingsniveau, roken, alcoholconsumptie en type werk).

\# Dit betreft het totaal aantal dagen verzuim gedurende vier jaar.

Tabel 3 Gemiddelde verzuimcijfers over de vierjarige onderzoeksperiode voor werknemers met een normaal gewicht, overgewicht of obesitas, opgesplitst in werknemers die niet regelmatig sporten en werknemers die regelmatig sporten.

\begin{tabular}{|c|c|c|c|c|}
\hline Ziekteverzuim \# & Totale groep & Normaal gewicht $^{1}$ & Overgewicht $^{2}$ & Obesitas $^{3}$ \\
\hline Geen regelmatige sportdeelname & $n=850$ & $n=508$ & $n=277$ & $n=65$ \\
\hline Frequentie zeer kort verzuim (1-2 dagen) & $1,5^{\star *}$ & 1,7 & 1,2 & 1,1 \\
\hline Frequentie kort verzuim (3-7 dagen) & 3,2 & 3,3 & 3,0 & 3,6 \\
\hline Frequentie middellang verzuim (8-21 dagen) & 1,6 & 1,4 & $1,8^{\star \star}$ & $2,4^{\star \star}$ \\
\hline Frequentie lang verzuim ( $\geq 22$ dagen) & 0,8 & 0,7 & 0,8 & $1,4^{\star \star}$ \\
\hline Frequentie totale verzuim & 7,0 & 7,1 & 6,7 & $8,5^{*}$ \\
\hline Totale verzuimduur (in dagen) & 91,2 & 83,9 & 91,7 & $145,9^{\star \star}$ \\
\hline Regelmatige sportdeelname & $n=341$ & $n=214$ & $\mathrm{n}=105$ & $n=22$ \\
\hline Frequentie zeer kort verzuim (1-2 dagen) & 1,9 & 2,0 & 1,7 & 1,6 \\
\hline Frequentie kort verzuim (3-7 dagen) & 3,1 & 3,0 & 3,1 & 3,6 \\
\hline Frequentie middellang verzuim (8-21 dagen) & 1,0 & 0,9 & 1,1 & 1,4 \\
\hline Frequentie lang verzuim ( $\geq 22$ dagen) & 0,6 & 0,6 & 0,6 & 0,8 \\
\hline Frequentie totale verzuim & 6,6 & 6,5 & 6,5 & 7,4 \\
\hline Totale verzuimduur (in dagen) & 68,2 & 64,8 & 69,4 & 95,3 \\
\hline
\end{tabular}

${ }^{1} \mathrm{BMI} 18,5-24,9 \mathrm{~kg} / \mathrm{m}^{2} ;{ }^{2} \mathrm{BMI} 25,0-29,9 \mathrm{~kg} / \mathrm{m}^{2} ;{ }^{3} \mathrm{BMI} \geq 30,0 \mathrm{~kg} / \mathrm{m}^{2}$

${ }^{\star} \mathrm{p}<0,05 ;{ }^{\star \star} \mathrm{p}<0,005$ obesitas/overgewicht versus normaal gewicht (multilevel analyse met bedrijf als cluster, en gecorrigeerd voor leeftijd, geslacht, opleidingsniveau, roken, alcoholconsumptie en type werk).

\# Dit betreft het totaal aantal dagen verzuim gedurende vier jaar.

lengte zelfgerapporteerd zijn, hetgeen een onnauwkeurigheid met zich meebrengt in het bepalen van de BMI. ${ }^{24}$ Door het longitudinale karakter van het onderhavige onderzoek, het gebruik van door het bedrijf geregistreerde verzuimdata en de door de fysiotherapeut gemeten lengte en gewicht, kunnen in het onderhavige onderzoek meer valide conclusies getrokken worden over de relatie tussen BMI en verzuim dan in voorafgaande onderzoeken.

De verschillen in verzuimduur en verzuimfrequentie (van acht dagen of langer) tussen obese werknemers en werknemers met een normaal gewicht blijken groter te zijn bij werknemers zonder regelmatige sportdeelname dan bij werknemers die regelmatig sportten. Deze interactie is echter alleen significant voor het lange verzuim. Het ontbreken van een significante interactie op verzuimduur kan te maken hebben met het geringe aantal obese werknemers die regelmatig sporten $(n=22)$. Het ontbreken van een samenhang tussen obesitas en verzuim bij werknemers die regelmatige sporten is in lijn met conclusies uit een review over de invloed van lichamelijke activiteit op de gezondheidseffecten van overgewicht en obesitas. Deze review toont aan dat regelmatig bewegen de meeste negatieve gezondheidseffecten van overgewicht en obesitas kan verminderen. ${ }^{16}$ Het effect op verzuim is niet bekeken in deze review.

Er zijn veel factoren die de relatie tussen obesitas en verzuim positief of negatief kunnen beïnvloeden, zoals voeding, cardiovasculaire fitheid en psychosociale factoren. ${ }^{3}$ In deze studie is slechts naar één factor - lichamelijk activiteit - gekeken. Verder onderzoek naar factoren die bepalen of en wanneer een werknemer met overgewicht of obesitas zich ziek meldt, is gewenst. Inzicht in de mechanismen waarom obesitas gepaard gaat met een hoger verzuim is immers van groot belang om de juiste interventies te kunnen formuleren.

Bij dit onderzoek kunnen enkele kanttekeningen gemaakt worden. Ten eerste kent het gebruikte design zijn beperkingen. Ook al zijn er longitudinale gegevens gebruikt, waarbij rekening is gehouden met de tijdsvolgorde van oorzaak en gevolg, harde uitspraken over de causaliteit van de relatie tussen BMI en verzuim blijven moeilijk. Zowel obesitas als verzuim kunnen immers veroorzaakt worden door een derde, niet gemeten, factor. Interventieonderzoek gericht op gewichtsreductie en het effect daarvan op verzuim is dan ook zeer gewenst. Ten tweede is de sportdeelname gebaseerd op zelfgerapporteerde gegevens. Sociale wenselijkheid en nauwkeurigheid van de informatie ('recall bias') kunnen geleid hebben tot een misclassificatie van de mate van lichamelijke activiteit. Het is echter al herhaaldelijk aangetoond dat zelfgerapporteerde gegevens over lichamelijke activiteit redelijk valide zijn en dat dit praktisch beter uitvoerbaar is in 
epidemiologisch onderzoek. ${ }^{25-28}$ Bovendien zijn er geen redenen om aan te nemen dat de misclassificatie in lichamelijke activiteit gerelateerd is aan de uitkomstmaat. Dit betekent dat als er sprake is van vertekening van de resultaten door de zelfrapportage van lichamelijke activiteit, dit eerder zal leiden tot een onderschatting dan een overschatting van de gevonden effecten. Ten derde zijn werknemers met incomplete gegevens over het verzuim, dat wil zeggen geen verzuimgegevens over vier jaar, niet meegenomen in de analyses. Het ontbreken van volledige gegevens kan samenhangen met een verandering van baan, maar ook met arbeidsongeschiktheid. Dit laatste kan leiden tot het zogenaamde 'healthy worker effect', aangezien minder gezonde werknemers eerder arbeidsongeschikt kunnen raken dan hun gezonde collega's. Uit aanvullende analyses blijkt dat de uitvallers meer ziektedagen hadden tijdens de basismeting dan de niet-uitvallers. Overgewicht en obesitas kwamen echter niet significant vaker voor onder de uitvallers dan onder de nietuitvallers. Er zijn daarom geen aanwijzingen dat de uitval een effect heeft op de gevonden relatie tussen obesitas en verzuim.

Het aantal mensen met overgewicht of obesitas neemt nog steeds toe. ${ }^{5}$ Dit vraagt om acties, niet alleen van het individu en de overheid, maar ook van het bedrijfsleven. Uit dit onderzoek blijkt dat obese werknemers fors meer verzuimen, naast mogelijke andere productiviteitsverliezen, maar hier is nog geen onderzoek naar verricht. Het bedrijfsleven wordt dus geconfronteerd met hogere kosten als gevolg van obesitas. Het is dan ook aan te bevelen dat bedrijven de huidige overheidsinspanningen gaan ondersteunen met een beleid op bedrijfsniveau gericht op de preventie van (een verdere toename van) overgewicht en obesitas. Reviews laten zien dat interventies gericht op gezonde voeding in combinatie met het stimuleren van bewegen effectief tot gewichtsreductie kunnen leiden. ${ }^{3,29}$ Ook zijn er aanwijzingen dat voorlichting en uitbreiding van gezonde keuzemogelijkheden in bedrijfsrestaurants kunnen bijdragen aan de preventie van overgewicht. ${ }^{3}$ Momenteel treft één op de zes bedrijven maatregelen om gezonde voedingsgewoonten tijdens het werk te bevorderen. ${ }^{30}$ Recent onderzoek wijst uit dat $32 \%$ van de bedrijven sport en beweegactiviteiten organiseert en 13\% concrete maatregelen neemt op het terrein van overgewicht. ${ }^{31}$ Dit mag op zich opmerkelijk genoemd worden, omdat er lange tijd grote terughoudendheid is geweest bij werkgevers om zich in te laten met de gevolgen van een meer of minder gezonde leefstijl van hun werknemers. Hierbij was de vraag op in hoeverre leefstijlinterventies de zorg zijn van de werkgever en waar de verantwoordelijkheden van de werknemer en de werkgever ophouden of beginnen. Er lijkt anno 2007 een kentering te constateren in de zin dat steeds meer werkgevers de zorg voor een gezond personeelsbestand als een belangrijke ondernemersdoelstelling zien. Dit uit zich onder meer in concepten als Maatschappelijk Verantwoord Ondernemen, Goed Werkgeverschap en Integraal Gezondheidsmanagement. Hierbij speelt het besef dat gezond personeel een randvoorwaarde is voor goed inzetbaar personeel een belangrijke rol. Uit dit onderzoek blijkt dat het stimuleren van bewegen daarbij op twee manieren een rol kan spelen. Waar al eerder was aangetoond dat werknemers die sporten minder verzuimen, ${ }^{17}$ blijkt uit het onderhavige onderzoek dat regelmatig sporten ook het ongunstige effect van overgewicht en obesitas op verzuim kan verminderen. Stimulering van meer en intensief bewegen kan dus op meerdere manieren effectief zijn om de gezondheid én productiviteit van werknemers te bevorderen.

Concluderend kan gesteld worden dat dit onderzoek aantoont dat overgewicht en met name obesitas leidt tot een hoger ziekteverzuim. Daarom is een een actief bedrijfsbeleid gewenst om overgewicht en obesitas aan te pakken niet alleen vanuit een gezondheidskundig perspectief, maar ook vanuit het perspectief van het bedriifsrendement. Bewegingsstimulering kan een attractieve invulling van dit beleid vormen.

\section{ABSTRACT}

Overweight, obesity, and absenteeism in the Dutch working population

Objectives: To determine whether Dutch overweight or obese workers have a higher duration and frequency of absenteeism than normal weight workers, considering their sports participation. Methods: Data were collected in a prospective cohort study $(n=1284)$. Company records provided absenteeism data. Multilevel-analyses were used to test whether duration and frequency of absenteeism were related to the Body Mass Index (BMI) and whether the interaction between BMI and sports participation was related to absenteeism. Results: In overweight subjects (BMI 25-30) only the frequency of absenteeism of 8 to 21 days was significantly higher than in normal weight subjects $(p<0,005)$. On average, obese subjects $(B M I \geq 30)$ were 14 days a year more absent than normal weight subjects $(p<0,005)$. Also the frequency of absenteeism of more than 7 days was significantly higher $(p<0,005)$. The differences in absenteeism between obese and normal weight subjects were larger for workers who did not practise sport regularly. Conclusions: Obese workers are more often and longer absent, especially when they do not practise sport regularly. An active company policy aimed at the prevention of overweight and obesity is needed, both from the view of health and from the view of business efficiency.

Key-words: obesity, overweight, absenteeism, sport, longitudinal study

\section{LITERATUUR}

1. CBS. http://www.cbs.nl, 2007.

2. WHO. Diet, nutrition and the prevention of chronic diseases. Report of a joint WHO/FAO expert consultation, 28 January 1 February 2002. Geneve: WHO, 2003.

3. Gezondheidsraad. Overgewicht en obesitas. Den Haag: Gezondheidsraad, 2003. Publicatie 2003/07.

4. Takken J, Polder JJ, Meerding WJ, Kommer GJ, Stokx LJ. Kosten van ziekten in Nederland. Hoofdlijnen. Bilthoven: RIVM, 2002. Rapport 270751004.

5. RIVM. Volksgezondheid Toekomst Verkenning, Nationaal 
Kompas Volksgezondheid. Bilthoven: RIVM, http://www.nationaalkompas.nl versie 3.6, 28 juni 2006.

6. RVZ. Advies Gezondheid en gedrag. Zoetermeer: Raad voor de Volksgezondheid en Zorg; 2002. Publicatie 02/14.

7. Aldana SG. Financial impact of health promotion programs: a comprehensive review of the literature. Am J Health Promot 2001;15:296-320.

8. Schmier JK, Jones ML, Halpern MT. Cost of obesity in the workplace. Scand J Work Environ Health 2006;32:5-11.

9. Bertera RL. The effects of behavioral risks on absenteeism and health care costs in the workplace. J Occup Med 1991;33:111924.

10. Bungum T, Satterwhite M, Jackson AW, Morrow JR. The relationship of Body Mass Index, medical costs, and job absenteeism. Am J Health Behav 2003;27:456-62.

11. Burton WN, Chen CY, Schultz AB, Edington DW. The economic costs associated with body mass index in a workplace. J Occup Environ Med 1998;40:786-92.

12. Burton WN, Conti DJ, Chen CY, Schultz AB, Edington DW. The role of health risk factors and disease on worker productivity. J Occup Environ Med 1999;41:863-77.

13. Narbro K, Jonsson E, Larsson B et al. Economic consequences of sick-leave and early retirement in obese Swedish women. Int J Obes 1996;20:895-903.

14. Pronk NP, Martinson B, Kessler RC et al. The association between work performance and physical activity, cardiorespiratory fitness, and obesity. J Occup Environ Med 2004;46:19-25.

15. Tucker EL, Friedman GM. Obesity and absenteeism: an epidemiological study of 10.825 employed adults. Am J Health Promot 1998;12:202-7.

16. Blair SN, Brodney S. Effects of physical inactivity and obesity on morbidity and mortality: current evidence and research issues. Med Sci Sports Exerc 1999;31(11 Suppl):S646-62.

17. Heuvel SG van den, Boshuizen HC, Hildebrandt VH, et al. Sporten, type werk, arbeidsverzuim en welbevinden: resultaten van een 3-jarige follow-up studie. Tijdschr Gezondheidswet 2003;81:256-64.

18. Bongers PM, Miedema MC, Douwes M. Longitudinaal onderzoek naar rug-, nek- en schouderklachten. Deelrapport 1: opzet en uitvoering van het onderzoek. Hoofddorp: TNO Arbeid; 2000.

19. Tsai SP, Gilstrap EL, Colangelo TA, Menard AK, Ross CE. Illness absence at on oil refinery and petrochemical plant. J Occup Environ Med 1997;39:455-62.
20. Moreau M, Valente F, Mak R et al. Obesity, body fat distribution and incidence of sick leave in the Belgian workforce: the Belstress study. Int J Obes 2004;28:574-82.

21. Hensing H. Swedish Council on Technology Assessment in Health Care (SBU). Chapter 4. Methodological aspects in sickness-absence research. Scand J Public Health 2004;63 Suppl:44-8.

22. Poppel MN van, Vet HC de, Koes BW, Smid T, Bouter LM. Measuring sick leave: a comparison of self-reported data on sick leave and data from company records. Occup Med 2002; 52:485-90.

23. Severens JL, Mulder J, Laheij RJ, Verbeek AL. Precision and accuracy in measuring absence from work as a basis for calculating productivity costs in The Netherlands. Soc Sci Med 2000; 51:243-9.

24. Nawaz H, Chan W, Abdulrahman M, Larson D, Katz DL. Selfreported weight and height: implications for obesity research. Am J Prev Med 2001;20:294-8.

25. Chasan-Taber L, Erickson JB, Nasca PC, Chasan-Taber S, Freedson PS. Validity and reproducibility of a physical activity questionnaire in women. Med Sci Sports Exerc 2002;34:98792.

26. Craig CL, Marshall AL, Sjöström M, Bauman AE, Booth $M L$, Ainsworth $B E$ et al. International physical activity questionnaire: 12 -country reliability and validity. Med Sci Sports Exerc 2003;35:1381-95.

27. Gionet NJ, Godin G. Self-reported exercise behavior of employees: a validity study. J Occup Med 1989;31:969-73.

28. Godin G, Jobin J, Bouillon J. Assessment of leisure time exercise behavior by self-report: a concurrent validity study. Can J Publ Health 1986;77:359-62.

29. Proper KI, Bakker I, Overbeek Kvan, Mechelen W van. De effectiviteit van interventies ter stimulering van gezonde voeding. TBV 2006;14:243-9.

30. Ybema JF, Sanders JMAF, Vroome E de. Cohortstudie Arbeid, Verzuim en Gezondheid (AVG); Methodologie en eerste resultaten 2004-2006. Hoofddorp: TNO, 2006.

31. Simons $M$, Verheijden MW, Hildebrandt VH. Bewegingsactiviteiten in bedrijven nemen toe. Arbo (geaccepteerd).

\section{CORRESPONDENTIEADRES}

MP Jans, TNO Kwaliteit van Leven, Postbus 2215, $2301 \mathrm{CE}$ Leiden, tel: 071-5181777, e-mail: marielle.jans@tno.nl Voor publicatie aanvaard in mei 2007. 